\section{Studies of children's probability learning behavior: VIII. Effect of punishment at two grade levels*}

\author{
STUART I. OFFENBACH \\ Purdue University, West Lafayette, Ind. 47907
}

Twenty-four fifth graders and 24 second graders participated in a $75: .25$ probability learning task under three different punishment conditions-0, 1 , and 3 units lost for any incorrect guess. The results indicated that these punishment amounts did not affect second-grade children's overall response tendencies or strategies. The older children, however, made more $A_{1}$ responses when the amount of punishment was increased from the immediately preceding level. The results were further evidence that older children are more sensitive to the experimental contingencies set up in probability learning tasks.

The investigation of losses associated with errors made by aduits in probability learning tasks has been conceptualized in terms of cost or risk (e.g., Myers, Reilly, \& Taub, 1961; Schnorr, Lipkin, \& Myers, 1966). When the cost of an error was increased, adults responded so as to reduce losses. However, one might also conceptualize the loss associated with errors as punishment. Again, Ss would be expected to minimize punishment by reducing the possibility of errors. All of these formulations imply that Ss in probability learning tasks should eliminate, or reduce the number of, their predictions that the less frequent (and less predictable) $E_{2}$ event would occur. This prediction has been supported in studies of probability learning with adult Ss, but has not been demonstrated when the Ss were children.

Previous studies of the effects of reinforcement on children's probability learning have concentrated on either reward alone (e.g., Brackbill, Kappy, \& Starr, 1962; Siegel \& Andrews, 1962) or both reward for correct responses and punishment for

\footnotetext{
*The research reported in this paper was supported by a grant to the author from the National Institute of Child Health and Human Development (HD-01639). The author would like to thank Mr. Roger $L$. Campbell, Principal of the Hillcrest School, Delphi, Ind., and his teaching staff for their cooperation in providing children to serve as Ss in this experiment.
} incorrect responses (e.g., Das \& Panda, 1963; Offenbach, 1964). In each of these studies, increased reward or reward/punishment led to an increase in $P\left(A_{1}\right)$ (probability of a prediction that the more frequent event, $E_{1}$, would occur). The purpose of the present study was to find out if children also minimized their losses in the face of increased punishment or cost by reducing the number of $A_{2}$ responses and increasing $A_{1}$ responses. SUBJECTS

Twenty-four second graders and 24 fifth graders served as $S s$ in this experiment. The children all were from the same rural school in the midwest.

\section{PROCEDURE}

Each child was tested individually in a two-room mobile lab parked adjacent to the school building. The children were brought to the lab by the $E$, who spent several minutes establishing rapport before administering the task instructions and three consecutive 60-trial probability learning tasks.

The stimuli were squares of red color, presented via a programmed rear-projector slide device. The first slide, which was of two squares (side by side), served as a signal for the child to make his response. The second slide (the $E_{1}$ or $E_{2}$ event) was a picture of one square on either the right or left side of the screen. The child's task was to choose on which side the single red square would be by pressing a button under the left or right square of the signal slide. The button pressed and the actual event occurrence was recorded automatically. The overall marginal probabilities of the $E_{1}$ and $\mathrm{E}_{2}$ events were .75 and .25 , respectively. Ten sequences of 60 trials each were constructed for use in this experiment. Each child was administered three different 60-trial sequences, each with a different amount of punishment. The punishment consisted of the removal of 0,1 , or 3 marbles following incorrect predictions of either the $\mathrm{E}_{1}$ or the $E_{2}$ event. Prior to the start of the experiment, each child was given 50 marbles. He also selected three 10-cent-type toys from a display, one of which had to be returned to the $E$ if the 50 marbles were lost. Pilot studies indicated that with 50 marbles, most children lost at least one toy during the experiment. At the end of the session, each child was told that he had done well in the game and the toy that was lost was returned. Thus, every child went back to the classroom with exactly three toys. There were six orders of presentation of the three punishment amounts $(0,1$, and 3$)$, and all six were used and included in the statistical analysis.

In the instructions, each child was told that every time he guessed wrong, he might lose (a) marble(s) and that if all the marbles initially given to him were lost, he would have to return one of his toys for more marbles (in order to continue playing the game). Four practice trials were given (with red squares pasted on blank note cards) in order to insure that the child behaved as though he understood the instructions. On each of these trials, the E socially reinforced the child and, on errors, told him that he might have lost marbles on that trial. Immediately after the practice trials, the E left the room briefly in order to initiate the programmed 60-trial sequence. Upon returning, the child was told how many marbles would be lost for each error in that sequence of trials. After 60 trials, another 60 -trial sequence was administered, and the $E$ described the new punishment contingencies. The child was returned to the classroom after the third 60-trial sequence. During the session, all questions were answered by rephrasing the relevant part of the instructions. While some of the children were unhappy with the punishment situation, none cried or asked to go back to the classroom prior to the end of the experimental session.

\section{RESULTS}

A 2 by 6 by 3 by 5 repeated measures analysis of variance with two variables between Ss (grade -2 and 5; 
Table 1

$P\left(A_{1}\right)$ for Each Amount of Punishment Occurring in Each Serial Position (Based on the Last 24 Trials)

\begin{tabular}{|c|c|c|c|c|c|}
\hline & & \multicolumn{3}{|c|}{ Position } & \multirow[b]{2}{*}{ Totals } \\
\hline & & $\mathbf{1}$ & 2 & 3 & \\
\hline \multicolumn{6}{|l|}{ Grade 2} \\
\hline Punish- & 0 & .583 & .578 & .656 & .606 \\
\hline ment & 1 & .646 & .672 & .604 & .641 \\
\hline $\begin{array}{l}\text { Amount } \\
\text { Totals }\end{array}$ & 3 & $\begin{array}{l}.635 \\
.622\end{array}$ & $\begin{array}{l}.594 \\
.614\end{array}$ & $\begin{array}{l}.614 \\
.625\end{array}$ & .614 \\
\hline \multicolumn{6}{|l|}{ Grade 5} \\
\hline Punish- & $\mathbf{0}$ & .609 & .677 & .766 & .684 \\
\hline ment & 1 & .640 & .755 & .740 & .712 \\
\hline Amount & 3 & .682 & .734 & .818 & .745 \\
\hline Totals & & .644 & .722 & .774 & \\
\hline
\end{tabular}

order of punishment amount-6 orders) and two variables within Ss (amount of punishment-0, 1, and 3; trials -5 blocks of 12) was computed on the number of $A_{1}$ responses. The analysis yielded the following significant effects and interactions: Trials, $\quad F(4,144)=44.02 ;$ Grade by Trials, $F(4,144)=2.74$; and Order by Punishment Amount, $F(10,72)=2.47$. Inspection of the data indicated that the $P\left(A_{1}\right)$ increased over trials for both grade levels, but that the increase was greater for the fifth-grade children. Inspection of the data of the Order by Punishment Amount interaction indicated that the $P\left(A_{1}\right)$ increased in each of the three sequential positions, regardless of the amount of punishment, and that the $P\left(A_{1}\right)$ was higher with increases in the amount of punishment administered (see Table 1). This observation was true particularly for the fifth-grade children. Thus, the punishment effects were not independent of increasing experience in the probability learning task.

A second set of analyses ( $t$ tests) was computed comparing the last 24 trials $P\left(A_{1}\right)$ from sequences immediately before and after an increase or decrease in the amount of punishment. Separate $t$ tests were computed for each grade level, since the differences between the fifth and second graders' data were greatest during the last 24 trials $\left[\mathrm{P}\left(\mathrm{A}_{1}\right)_{\mathrm{G}} \mathrm{rd} 5=.714 ; \mathrm{P}\left(\mathrm{A}_{1}\right)_{\mathrm{Grd}} \mathrm{Gr}\right.$ $=.618]$. The analyses of the

Table 2

Terminal Levels of $\mathbf{P}\left(\mathbf{A}_{1}\right)$ Before and After Both Increases and Decreases in the Amount of Punishment

\begin{tabular}{|c|c|c|c|c|}
\hline & \multicolumn{2}{|c|}{$\begin{array}{l}\text { Punișhment } \\
\text { Increase }\end{array}$} & \multicolumn{2}{|c|}{$\begin{array}{c}\text { Punishment } \\
\text { Decrease }\end{array}$} \\
\hline & Before & After & Before & After \\
\hline Grade 2 & .618 & .618 & .618 & .622 \\
\hline Grade 5 & .663 & .772 & .703 & .724 \\
\hline
\end{tabular}

there was no change in the $P\left(A_{1}\right)$ following any increase or any decrease in the amount of punishment (both $t<1.00$; see Table 2). For the fifth-grade data, however, there was a significant increase in the $P\left(A_{1}\right)$ when the amount of punishment increased from the immediately preceding 60-trial sequence of events $(t=3.96$; df $=23$ ). Inspection of the data indicated that the change in $P\left(A_{1}\right)$ for these children was the same regardless of whether punishment increased one, two, or three units. There was, however, no change in the $P\left(A_{1}\right)$ when the amount of punishment decreased $(t<1.00)$. These analyses indicated that changes in the amount of punishment only affected the probability learning behavior of fifth-grade children. Additional analyses of selected intratask measures of response strategies also failed to reveal any statistically significant effects of punishment (e.g., response alternation, "win-stay," and "lose-shift" strategies).

\section{DISCUSSION}

The results of this study indicated that second-grade children's probability learning behavior was not influenced by the manipulation of punishment and that fifth-grade children altered their choice behavior only when the amount of punishment was increased. Specifically, the younger children made the same number of $A_{1}$ responses (in the last 24 trials) regardless of the amount of experience in the task, the absolute amount of punishment, and the change in level of punishment within the task. Thus, the amounts of punishment used in this study were not sufficient to affect probability learning behavior in second-grade children. Whether a larger difference in punishment amount, a more severe punishment, or a different procedure for administering punishment would produce differences in responding is a matter for future investigation.

The terminal $P\left(A_{1}\right)$ for the fifth graders increased both with experience and punishment (Table 1). Early in probability learning (the first 60-trial sequence), increased punishment was associated with more $A_{1}$ responses. As the children became more familiar with the task, the amount of punishment became less influential. At the same time, however, the fifth graders were not insensitive to the increases in the amount of punishment. These increases led to more $A_{1}$ responses. Decreases in punishment, on the other hand, produced no changes in behavior. It appeared that once the fifth-grade children adopted a response strategy, it was used continuously unless the cost of an error was increased.
In summary, these data indicated that the increases in punishment and procedures used here did not lead children to maximize reward (by eliminating $\mathrm{A}_{2}$ responses), as adults have done in similar settings. However, the older children did respond to increases in the amount of punishment. They appeared to be more sensitive to the intratask manipulations of the experimental contingencies by changing response strategies with both increased punishment and more experience. This behavior pattern was consistent with response patterns observed in an earlier study where it was found that older children were more sensitive than second graders to the trial-by-trial task contingencies (Offenbach, 1968). This finding was interpreted in terms of the younger children's inability to assimilate and/or use whatever information was available in the task. In the present study, the information added by the punishment was not utilized by the younger children. Thus, all negative feedback or punishment led to the same behavior, regardless of how much experience the child had in the task. However, if the punishment had been administered in a different way, greater behavioral changes might have occurred. One might, for example, use a within-Ss ${ }^{\dagger}$ paradigm with punishment levels varied within blocks of trials (see Schnorr et al, 1966) or with different amounts of punishment for incorrect guesses of the two events (see Myers et al, 1961). With either of these paradigms, more could be learned about the effects of punishment in children's probability learning behavior.

\section{REFERENCES}

BRACKBILL, Y., KAPPY, M. S., \& STARR, R. H. Magnitude of reward and probability learning. Joumal of Experimental Psychology, 1962,63. 32-35.

DAS, J. P., \& PANDA, K. C. Two-choice learning in children and adolescents under reward and nonreward conditions. Journal of General Psy chology, 1963, 68, 203-211.

MYERS, J. L., REILLY, R. E., \& TAUB, H. A. Differential cost, gain, and relative frequency of reward in a sequential choice situation. Journal of Experimental Psychology, 1961,62, 357-360.

OFFENBACH, S. 1. Studies of children's probability learning behavior: I. Effect of reward and punishment at two age levels. Child Development, 1964, 35, 709.715.

OFFENBACH, S. I. Studies of children's probability learning behavior: $V$. Effect of event sequences. Journal of Experimental Child Psychology, 1968, 6 , $460-469$.

SCHNORR, J. A., LIPKIN, S. G., \& MYERS, J. L. Level of risk in probability learning: Within- and between-subjects designs. Journal of Experimental Psychology, 1966, 72, 497-500.

SIEGEL, S., \& ANDREWS, J. M. Magnitude of reinforcement and choice behavior in children. Journal of Experimental Psychology, 1962, 63, 337-341. 